\title{
Mortality outcomes of low-dose computed tomography screening for lung cancer in urban China: a decision analysis and implications for practice
}

Zixing Wang ${ }^{1 \dagger}$, Wei Han ${ }^{1 \dagger}$, Weiwei Zhang ${ }^{1}$, Fang Xue ${ }^{1}$, Yuyan Wang ${ }^{1}$, Yaoda Hu' ${ }^{1}$, Lei Wang ${ }^{1}$, Chunwu Zhou ${ }^{2}$, Yao Huang ${ }^{2}$, Shijun Zhao ${ }^{2}$, Wei Song ${ }^{3}$, Xin Sui ${ }^{3}$, Ruihong Shi ${ }^{4}$ and Jingmei Jiang ${ }^{1 *}$

\begin{abstract}
Background: Mortality outcomes in trials of low-dose computed tomography (CT) screening for lung cancer are inconsistent. This study aimed to evaluate whether CT screening in urban areas of China could reduce lung cancer mortality and to investigate the factors that associate with the screening effect.

Methods: A decision tree model with three scenarios (low-dose CT screening, chest X-ray screening, and no screening) was developed to compare screening results in a simulated Chinese urban cohort (100,000 smokers aged 45-80 years). Data of participant characteristics were obtained from national registries and epidemiological surveys for estimating lung cancer prevalence. The selection of other tree variables such as sensitivities and specificities of low-dose CT and chest X-ray screening were based on literature research. Differences in lung cancer mortality (primary outcome), false diagnoses, and deaths due to false diagnosis were calculated. Sensitivity analyses were performed to identify the factors that associate with the screening results and to ascertain worst and optimal screening effects considering possible ranges of the variables.
\end{abstract}

Results: Among the 100,000 subjects, there were 448, 541, and 591 lung cancer deaths in the low-dose CT, chest $X$-ray, and no screening scenarios, respectively (17.2\% reduction in low-dose CT screening over chest X-ray screening and $24.2 \%$ over no screening). The costs of the two screening scenarios were 9387 and 2497 false diagnoses and 7 and 2 deaths due to false diagnosis among the 100,000 persons, respectively. The factors that most influenced death reduction with low-dose CT screening over no screening were lung cancer prevalence in the screened cohort, lowdose CT sensitivity, and proportion of early-stage cancers among low-dose CT detected lung cancers. Considering all possibilities, reduction in deaths (relative numbers) with low-dose CT screening in the worst and optimal cases were 16 (5.4\%) and 288 (40.2\%) over no screening, respectively.

Conclusions: In terms of mortality outcomes, our findings favor conducting low-dose CT screening in urban China. However, approaches to reducing false diagnoses and optimizing important screening conditions such as enrollment criteria for screening are highly needed.

Keywords: Lung cancer, Low-dose CT, Screening, Mortality outcome, Decision analysis

\footnotetext{
*Correspondence: jingmeijiang238@hotmail.com

${ }^{\dagger}$ Zixing Wang and Wei Han contributed equally to this work

${ }^{1}$ Institute of Basic Medical Sciences, Chinese Academy of Medical

Sciences, Beijing 100005, P. R. China

Full list of author information is available at the end of the article
} 


\section{Background}

Lung cancer is the most common malignant tumor and the dominant cause of cancer-related deaths in China [1]. The 5-year overall survival rate of patients with lung cancer remains approximately $15 \%-18 \%$ even in developed countries [2], whereas for patients who undergo surgical resection of stage I cancer this rate is well above $70 \%$ [3], highlighting the urgent need for early detection and treatment. First introduced in the 1990s, low-dose computed tomography (CT) has become the most promising approach for lung cancer screening [4]. Increasing number of screening programs in North America [5], Japan [6], and Europe [7-14] have greatly augmented the volume of the evidence base concerning low-dose CT screening practice. However, in China, a country with $36 \%$ of all lung cancers worldwide [15], mortality outcome, which is the most important measure for assessing screening effects, has not yet been evaluated despite numerous preliminary studies on diagnostic accuracy [16].

The United States National Lung Screening Trial (NLST) has reported an encouraging 20\% reduction in lung cancer mortality with low-dose CT screening over chest X-ray screening [5]. However, uncertainties remain regarding the mortality outcomes of screening programs because of controversial results from other countries [7-14]. Two randomized controlled trials (RCTs) from Italy [7, 8] and one from Denmark [9] reported equal or slightly increased mortalities (not statistically significant) for low-dose CT screening compared with no screening. Five ongoing RCTs (from Germany [10], Italy [11], France [12], the Netherlands, Belgium and Hungary [13], and the United Kingdom [14]) have not yet released their mortality outcomes. Outcomes of screening programs may vary between settings because of diversity in participants' characteristics and healthcare service conditions [17]. Therefore, there is a need to investigate whether early detection by low-dose CT screening could reduce lung cancer mortality in China and to investigate the variations in screening effects before introducing such screening countrywide. This study aimed to analyze differences in lung cancer mortality between three scenarios using available data from China and to identify factors that most strongly influence the outcomes in low-dose CT screening.

\section{Methods}

\section{Study population}

In this study, we simulated a cohort of 100,000 urban residents and offered them one-off lung cancer screening (baseline screening, i.e., prevalence screening). The age and sex structures of this cohort were based on data from the China Population \& Employment Statistics Yearbook
2014 [18]. According to data on lung cancer incidence reported by the National Cancer Registry 2012 [19], age criterion for this cohort was set at 45-80 years. As there is currently no high-quality evidence-based recommendation on inclusion criteria for lung cancer screening in China [20], we adopted the relatively relaxed criterion of "smokers" as a requirement of the 100,000 participants, regardless of daily smoking dose, smoking years, and cumulative pack-years (this choice of criterion was made also because it was used in national surveys on smoking in China [21]). No other restrictions were imposed such as family history of lung cancer or individual history of pulmonary disease. However, we did exclude lung cancer screening for special categories, such as patients with tuberculosis or human immunodeficiency virus infection and individuals with work-place exposure to asbestos, coal dust, nuclear radiation, organic solvents, and fuels.

\section{Decision tree model}

Decision analysis is widely used to make choices between different paths in Chaotics and uncertain conditions [22], especially in healthcare studies where medical outcomes such as mortality depend on a great number of potentially influencing factors [23]. To identify the best approach to detecting lung cancer so as to improve outcomes and to test the degree of uncertainty, we considered and compared the following three possible paths for lung cancer detection and treatment (Fig. 1).

\section{Low-dose CT screening scenario}

Individuals with findings suggestive of lung cancer on low-dose CT images were asked to undergo further investigation, such as bronchoscopy and percutaneous biopsy, to determine the diagnosis and then either accept or refuse surgical treatment. Additionally, we set up branches in the path corresponding with "missed diagnosis" caused by false negative imaging results (merging into the no screening path described below), "false diagnosis" caused by false positive imaging results, and the "over diagnosis" issue (individuals with indolent cancer who live for a long time though untreated) recently raised by researchers [24].

\section{Chest $X$-ray screening scenario}

The overall path was similar to that in the low-dose CT screening scenario, with the only difference being that the variables were adjusted to chest X-ray screening.

\section{No screening scenario}

Individuals with lung cancer detected and further diagnosed according to symptoms or medical examinations for other diseases took the usual health care treatment path. 


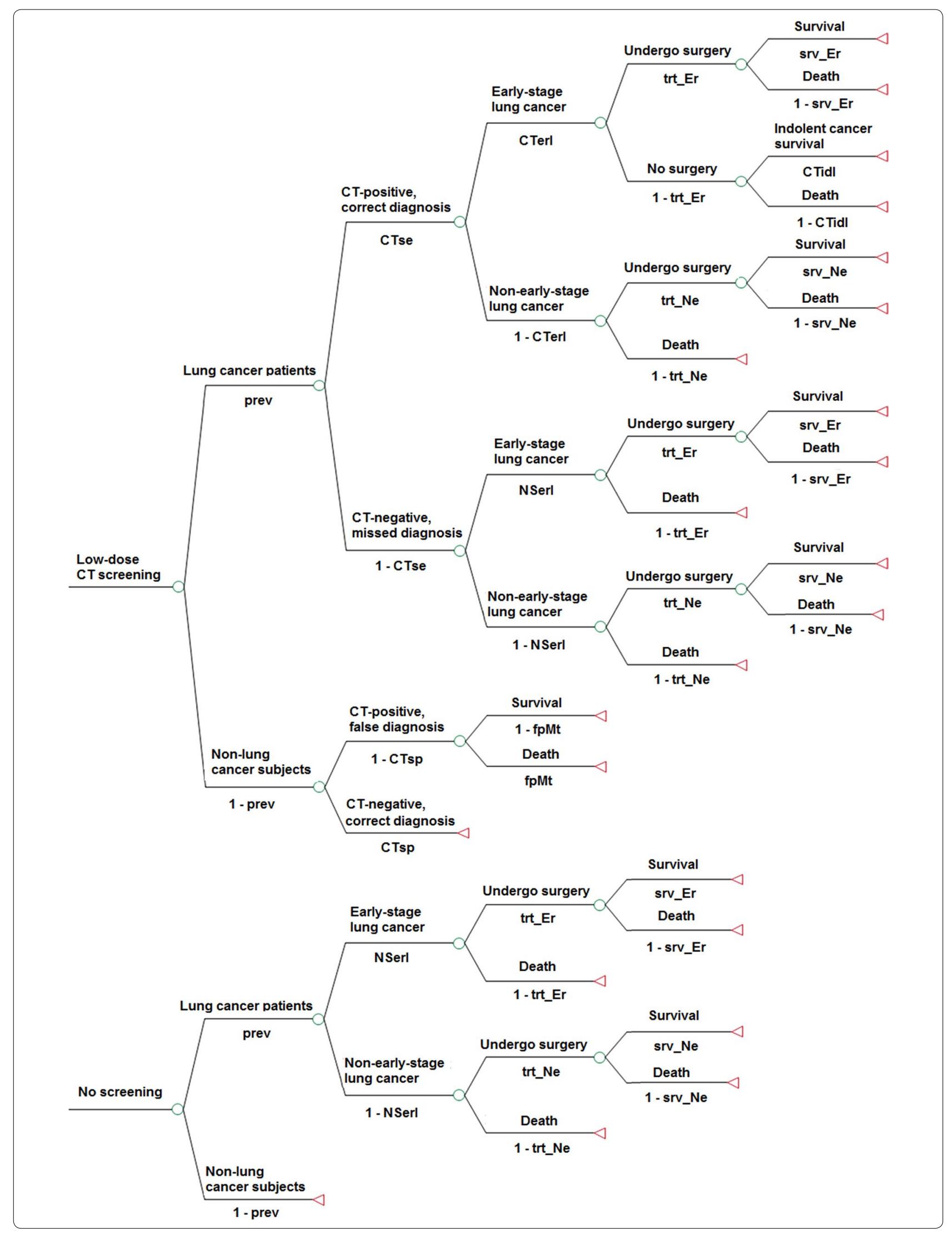


(See figure on previous page.)

Fig. 1 Decision tree model for the analysis of lung cancer mortality, false positive diagnosis, and death due to false diagnosis with low-dose computed tomography (CT) screening and no screening. Chest X-ray screening is similar to low-dose CT screening and is not shown. prev lung cancer prevalence in the screened cohort, CTse sensitivity of low-dose CT, CTsp specificity of low-dose CT, CTerl proportion of early-stage cancers among lung cancers detected with low-dose CT, NSerl proportion of early-stage cancers among lung cancers detected with no screening, fpMt death possibility due to false diagnosis and invasive treatment, trt_Er acceptance rate of surgery for individuals with early-stage lung cancers, trt_Ne acceptance rate of surgery for individuals with non-early-stage lung cancers, Srv_Er survival possibility of individuals with resected early-stage lung cancer, CTidl proportion of indolent cancers among lung cancers detected with low-dose CT, srv_Ne survival possibility of individuals with resected non-early-stage lung cancer

All the three scenarios were stratified by early (stage I for non-small cell lung cancers and limited stage for small cell lung cancers) and non-early stage cancers, considering the impact of disease stage on the acceptance rate of surgery and survival possibility after surgery.

Additionally, the following assumptions were made for the decision tree. First, surgery is a determinant for lung cancer mortality (except for indolent cancers), and although non-surgical treatments could prolong patient survival, their small impact on the final outcomes was not taken into account [25]. Second, a 5-year time span was adopted. As the screened cohort had a high competing risk from other diseases, deaths beyond the 5-year range were not considered in the outcome evaluation.

\section{Parameter setting}

Table 1 lists all the variables and the estimated values of parameters used in the decision tree. Specifically, the selection of screening parameters of low-dose $\mathrm{CT}$ and chest $\mathrm{X}$-ray and the clinical parameters of diagnosis and treatment path were based on a systematic search of literatures (mainly from studies in China, together with a few studies in other countries, all extracted from MEDLINE, EMBASE, CNKI, and ChinaInfo databases and published between January 1990 and February 2016). Quality-weighted metaanalyses were performed to obtain the average estimate of parameter for each tree variable for base-case analysis (analysis based on the most likely estimates of parameters) and a reliable range for sensitivity analysis.

Lung cancer prevalence of the screened cohort was calculated as follows.

First, age- and sex-specific lung cancer incidences in the general Chinese urban population $\left(I_{\mathrm{G}}\right)$ were extracted from the China Cancer Registry 2012 (urban data) at age intervals of 5 years [19]. Next, the incidence of the screened cohort $\left(I_{\mathrm{S}}\right)$ for each age and sex group was calculated using the formula below:

$$
I_{\mathrm{S}}=\frac{\mathrm{OR} \times I_{\mathrm{G}}}{1+(\mathrm{OR}-1) \times R}
$$

where $R$ is the age- and sex-specific rate of smoking reported in the Global Adult Tobacco Survey (GATS) China 2010 Country Report [26] and OR (2.85 for men and 2.33 for women) is the odds ratio according to metaanalysis results based on five case-control studies in China that used newly incident lung cancers to estimate the degree of association between smoking and lung cancer between 2001 and 2014 [27-31].

Further, because lung cancer prevalence is relatively stable in China, the following formula was used to calculate age- and sex-specific lung cancer prevalence in the screened cohort $\left(P_{\mathrm{S}}\right)$ :

$$
P_{\mathrm{S}}=I_{\mathrm{S}} \times t
$$

where $t=3.0$ years (sensitivity range $1.5-3.5$ years) is the average course of lung cancer [32].

Finally, the overall prevalence of lung cancer in the screened cohort aged 45-80 years was calculated by standardizing the age- and sex-specific prevalence using the actual demographical structure reported in the China Population \& Employment Statistics Yearbook 2014 [18] and the smoking rates in the GATS China 2010 Country Report [26].

Quality-adjusted life year (QALY) [33] was analyzed for the three scenarios over a 5-year time span. Quality utilities that were incorporated into the model were 0.76 for individuals without lung cancer [34], 0.62 for the time from detection of lung cancer to surgical treatment [35], 0.67 for early- and 0.55 for non-early-stage cancer patients after surgical treatment [35], and 0.56 for those who refused surgical treatment after detection, regardless of cancer stage and presence of other treatments [35]. We used an average delay of 0.5 years to lung cancer detection in the no screening scenario compared with the two screening scenarios, and incorporated an interval of 0.25 years for all the individuals with lung cancer from detection to surgical treatment (by expert consultation). The mean survival within the 5 -year time span was estimated as 4.31 and 2.99 years for individuals with resected early- and non-early-stage cancers, respectively [3], and as 2.78 and 0.71 years for individuals with non-resected early- and non-early-stage cancers, respectively [36].

Additionally, to explore the influences of criteria of age, smoking, and sex on the prevalence of lung cancer in the screened cohort (and therefore on screening outcomes), with the same procedures described above, we further 
Table 1 Parameter settings in the decision tree for lung cancer screening in urban China

\begin{tabular}{|c|c|c|c|c|c|}
\hline \multirow[t]{2}{*}{ Variable } & \multirow[t]{2}{*}{ Definition } & \multirow{2}{*}{$\begin{array}{l}\text { Base-case } \\
\text { analysis (\%) }\end{array}$} & \multicolumn{2}{|c|}{ Sensitivity analysis (\%) } & \multirow[t]{2}{*}{ Reference source } \\
\hline & & & Lower limit & Upper limit & \\
\hline prev & Lung cancer prevalence in the screened cohort & 0.7666 & 0.3833 & 0.8943 & Calculated from $[18,22,26,32,53]$ \\
\hline CTse & Sensitivity of low-dose CT & 87.7 & 71.8 & 100.0 & Meta of $[21,54-66]$ \\
\hline CTsp & Specificity of low-dose CT & 90.6 & 86.3 & 91.1 & Meta of $[55,57-60,63,66-69]$ \\
\hline XRse & Sensitivity of chest X-ray & 65.1 & 61.4 & 69.4 & Meta of $[21,55-57,60,62-65,70]$ \\
\hline XRsp & Specificity of chest X-ray & 97.5 & 89.5 & 98.4 & Meta of $[55,57,60,63,69,71,72]$ \\
\hline CTerl & $\begin{array}{l}\text { Proportion of early-stage cancer }{ }^{\mathrm{a}} \text { among lung cancers } \\
\text { detected with low-dose CT }\end{array}$ & 70.1 & 63.9 & 76.0 & [73] \\
\hline XRerl & $\begin{array}{l}\text { Proportion of early-stage cancer }{ }^{\mathrm{a}} \text { among lung cancers } \\
\text { detected with chest X-ray }\end{array}$ & 46.6 & 38.1 & 55.0 & {$[73,74]$} \\
\hline NSerl & $\begin{array}{l}\text { Proportion of early-stage cancers }{ }^{a} \text { among lung cancers } \\
\text { detected with no screening }\end{array}$ & 27.9 & 23.2 & 32.7 & Meta of $\left[24,55,76-7952^{d}, 75^{e},\right]$ \\
\hline CTidl & $\begin{array}{l}\text { Proportion of indolent cancers }{ }^{b} \text { among lung cancers } \\
\text { detected with low-dose CT }\end{array}$ & 25.0 & 15.0 & 35.0 & [20] \\
\hline XRidl & $\begin{array}{l}\text { Proportion of indolent cancers }{ }^{b} \text { among lung cancers } \\
\text { detected with chest X-ray }\end{array}$ & 20.0 & 15.0 & 25.0 & {$[20]$} \\
\hline trt_Er & Acceptance rate of surgery for early-stage lung cancers ${ }^{a}$ & 72.5 & 68.2 & 76.0 & Meta of [80-82] \\
\hline trt_Ne & $\begin{array}{l}\text { Acceptance rate of surgery for non-early-stage lung } \\
\text { cancers }^{\mathrm{a}}\end{array}$ & 28.6 & 28.2 & 30.6 & Meta of [80-82] \\
\hline srv_Er & $\begin{array}{l}\text { Survival possibility of individuals with resected early- } \\
\text { stage lung cancer }\end{array}$ & 72.7 & 62.3 & 75.7 & Meta of $[3,35,83]$ \\
\hline srv_Ne & $\begin{array}{l}\text { Survival possibility of individuals with resected non- } \\
\text { early-stage lung cancer }{ }^{c}\end{array}$ & 39.7 & 30.2 & 42.4 & Meta of $[3,35,83]$ \\
\hline fpMt & $\begin{array}{l}\text { Death possibility due to false diagnosis and invasive } \\
\text { treatment }\end{array}$ & 0.07 & 0.00 & 0.13 & [84] \\
\hline
\end{tabular}

CT computed tomography

a Stage I for non-small cell lung cancers and limited stage for small cell lung cancers were defined as early-stage cancers, and others as non-early-stage cancers

${ }^{b}$ Lung cancers such as bronchioloalveolar carcinoma that did not affect survival for a long time if left untreated were defined as indolent cancers

c Based on 5-year estimation

d Seven studies that were conducted among the Chinese population with complete stage information [85-91] in this meta-analysis were included and reanalyzed in this study

e Eight studies with complete stage information [92-99] in this meta-analysis were included and reanalyzed in this study

calculated different $\mathrm{P}_{S}$ for 12 plausible sub-intervals within the 45-80-year age range to determine the best lower and upper age limits in terms of mortality, and $\mathrm{P}_{S}$ for men and women separately, each with 11 different proportions of smoking among the enrolled individuals if screening was not restricted to smokers.

\section{Statistical analysis}

Lung cancer death was the primary outcome measure in this study. Using base-case analysis, we calculated the absolute and relative reductions in lung cancer deaths with low-dose CT screening over chest X-ray screening and no screening. False diagnosis, death due to false diagnosis, and QALY as secondary outcome measures were simultaneously calculated and compared. Univariate sensitivity analysis (by separately letting each variable in the model fluctuate within its lower and upper ranges for sensitivity analysis while keeping the others at their base-case analysis values) was performed to investigate the influences of screening conditions on outcomes in different scenarios, and a tornado diagram was plotted to vividly display the magnitude of the influence of each variable (relative importance of the variables was ranked by percentages of variations in the outcomes due to their own influence over the variation summary due to influence of all variables). Optimal and worst cases of reductions in lung cancer deaths with low-dose CT screening over other scenarios were determined by considering combinations of all possible ranges of the variables. All the analyses were performed with Treeage Pro 2011 software (TreeAge Software, Inc, Williamstown, MA, USA).

\section{Results}

\section{Base-case analysis}

Age and sex distribution of the simulated cohort in the base-case analysis is displayed in Table 2. Among these 
100,000 urban smokers (94,012 men and 5988 women) aged $45-80$ years, 721 men and 46 women had lung cancers. As to the outcomes in the three scenarios for the same cohort, the number of lung cancer deaths in the low-dose CT screening scenario was 448 , a reduction of 143 (24.2\%) over the no screening scenario (591 lung cancer deaths); meanwhile, low-dose CT screening resulted in 9387 false diagnoses and 7 deaths due to false diagnosis. In the chest X-ray screening scenario, there were 541 lung cancer deaths, a reduction of $50(8.5 \%)$ over the no screening scenario, and chest X-ray screening resulted in 2497 false diagnoses and 2 deaths due to false diagnosis. There were 93 fewer lung cancer deaths (17.2\%) in the low-dose CT screening scenario than in the chest $\mathrm{X}$-ray screening scenario; however, false diagnoses and deaths due to false diagnosis were 3.76 and 3.50 times higher, respectively, in the former scenario. Additionally, QALYs were 378,427 years in low-dose CT screening, 378,280 years in chest X-ray screening, and 378,177 years in no screening scenarios, that is, low-dose CT screening resulted in slightly more QALYs: 147 years over chest $\mathrm{X}$-ray screening and 250 years over no screening.

\section{Univariate sensitivity analysis}

Lung cancer prevalence in the screened cohort was the factor that most strongly influenced the death reduction with low-dose CT screening over no screening (Fig. 2). The variation in prevalence (from 383.3 to 894.3 per $100,000)$ led to a great variation in the absolute reduction in lung cancer deaths (from 68 to 168), being responsible for $61.3 \%$ of the all-variable influence. Other six factors besides the lung cancer prevalence contributed positively to the death reduction benefit in the following order: low-dose CT sensitivity (14.3\% of the all-variable influence), proportion of early-stage cancers among lung cancers detected with low-dose CT (9.5\%), survival possibility of individuals with resected early-stage lung cancer (4.7\%), proportion of indolent cancers among lung cancers detected with low-dose CT (4.1\%), acceptance rate of surgery for early-stage lung cancers (0.3\%), and specificity of low-dose CT $(0.1 \%)$. These six factors together contributed $33.0 \%$ to the variation in reduction in lung cancer deaths. Four factors were negatively related with reduction in lung cancer deaths with lowdose CT screening over no screening, namely proportion of early-stage cancers among lung cancers detected with no screening $(4.3 \%)$, possibility of death due to false diagnosis and invasive treatment $(0.9 \%)$, survival possibility of patients with resected non-early-stage lung cancer $(0.6 \%)$, and acceptance rate of surgery for non-early-stage lung cancers $(0.01 \%)$; however, their cumulative influence was subtle (5.8\%).

For the secondary outcome measures (not shown in figures), the factor that most influenced the number of false diagnosis was specificity of low-dose CT (negatively contributing $99.9 \%$ to variation in increased false diagnoses); lung cancer prevalence had a tiny negative influence $(0.01 \%)$. Three factors were related to number of deaths due to false diagnosis with low-dose CT screening, namely, death possibility due to false diagnosis $(93.0 \%$, positive), low-dose CT specificity (7.0\%, negative), and lung cancer prevalence $(0.01 \%$, negative). The factor that most influenced DALY was lung cancer prevalence $(58.7 \%)$, followed by low-dose CT sensitivity (13.5\%), low-dose CT specificity (11.0\%), and proportion of early-stage cancers among lung cancers detected with

Table 2 Age and sex distribution of the simulated smoking cohort for base-case analysis

\begin{tabular}{|c|c|c|c|c|c|c|c|c|}
\hline \multirow[t]{2}{*}{ Age group (years) } & \multicolumn{2}{|c|}{$\begin{array}{l}\text { General population } \\
\text { structure }(\%)^{\text {a }}\end{array}$} & \multicolumn{2}{|c|}{$\begin{array}{l}\text { General population } \\
\text { smoking rate }(\%)^{\mathbf{b}}\end{array}$} & \multicolumn{2}{|c|}{$\begin{array}{l}\text { No. of smokers for base-case } \\
\text { analysis (total }=100,000 \text { ) }\end{array}$} & \multicolumn{2}{|c|}{$\begin{array}{l}\text { No. of lung cancer } \\
\text { patients in } 100,000 \\
\text { smokers for base- } \\
\text { case analysis }\end{array}$} \\
\hline & Men & Women & Men & Women & Men & Women & Men & Women \\
\hline $45-49$ & 13.4 & 12.6 & 69.5 & 2.9 & 29,489 & 1157 & 64 & 3 \\
\hline $50-54$ & 10.1 & 9.4 & 63.1 & 4.1 & 20,307 & 1224 & 88 & 4 \\
\hline $55-59$ & 9.3 & 9.3 & 61.9 & 3.0 & 18,356 & 884 & 123 & 5 \\
\hline $60-64$ & 6.8 & 7.1 & 54.9 & 2.5 & 11,793 & 566 & 126 & 4 \\
\hline $65-69$ & 4.4 & 4.7 & 45.7 & 8.1 & 6403 & 1200 & 109 & 13 \\
\hline $70-74$ & 3.2 & 3.5 & $42.3^{c}$ & $4.3^{c}$ & 4259 & 476 & 103 & 8 \\
\hline $75-80$ & 2.9 & 3.4 & $36.7^{c}$ & $4.5^{c}$ & 3405 & 481 & 108 & 9 \\
\hline Summary & 50.1 & 49.9 & 59.1 & 3.8 & 94,012 & 5988 & 721 & 46 \\
\hline
\end{tabular}

\footnotetext{
a Obtained from Sampling Survey Data of the National Population Change in 2013 in China Population \& Employment Statistics Yearbook [18]

b Obtained from Global Adult Tobacco Survey (GATS) China 2010 Country Report [26]

c Predicted using linear regression
} 


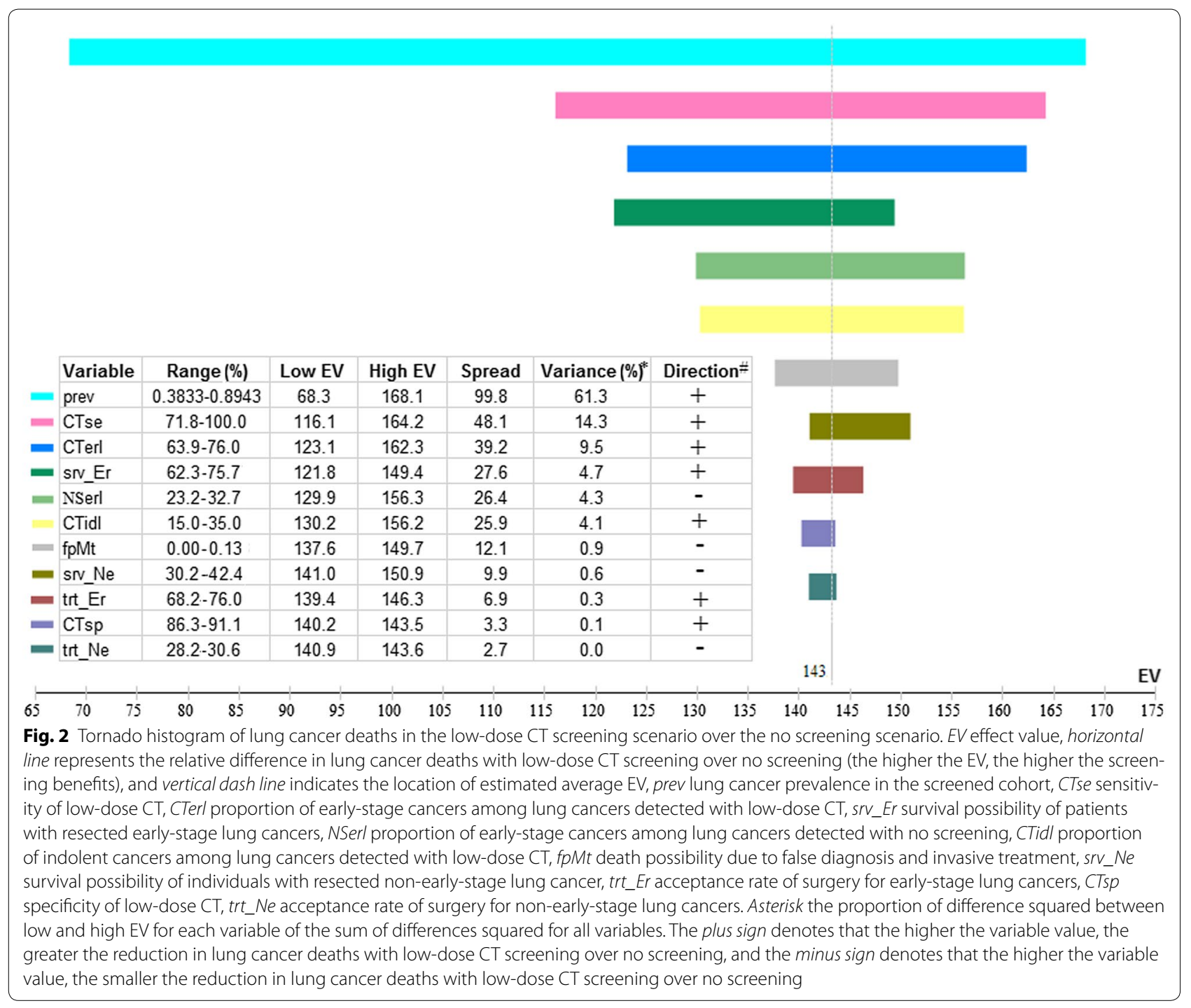

low-dose CT (10.0\%; all positive). Notably, a threshold of QALY was detected in lung cancer prevalence (436 per 100,000); the gain of QALY in low-dose CT screening over no screening would diminish if screening was performed among populations with a low prevalence of lung cancer.

\section{Worst and optimal case analysis}

Considering the possible ranges of all influential factors, reductions in lung cancer deaths with low-dose CT screening over no screening were 281 versus 297 (16 absolute reduction, $5.4 \%$ relative reduction) in the worst case and 428 versus 716 (288, 40.2\% reduction) in the optimal case, and those over chest X-ray screening were 281 versus $270(-11,-4.1 \%$ reduction) in the worst case and 428 versus 669 (241,36.0\% reduction) in the optimal case.

\section{Influence of age criteria}

The influences of upper and lower age limits on prevalence of lung cancer in the screened cohort and on differences in numbers of lung cancer deaths between the three scenarios are shown in Table 3. Relative to no screening, more than 200 fewer lung cancer deaths (24.5\% relative reduction) could be achieved by setting the age criteria for low-dose CT screening at 55-75, $55-80,60-70,60-75$, or $60-80$ years. Similarly, these intervals for age criteria could lead to more than 130 fewer deaths (17.5\% relative reduction) with low-dose CT screening over chest X-ray screening. However, some of these age intervals covered relatively small portions of the total lung cancer patients among the whole population of $45-80$ years old, e.g., only $32.9 \%$ and $47.3 \%$ of patients with lung cancer would be covered if age criteria of 60-70 and 60-75 years were adopted, respectively. 
Table 3 Prevalence of lung cancer among 100,000 smokers and predicted lung cancer deaths in low-dose CT, chest X-ray, and no screening scenarios with different age inclusion criteria

\begin{tabular}{|c|c|c|c|c|c|c|c|}
\hline \multirow{2}{*}{$\begin{array}{l}\text { Age interval } \\
\text { (years) }\end{array}$} & \multirow{2}{*}{$\begin{array}{l}\text { Lung cancer } \\
\text { prevalence } \\
\text { (per 100,000) }\end{array}$} & \multirow{2}{*}{$\begin{array}{l}\text { Target coverage } \\
(\%)^{\mathrm{a}}\end{array}$} & \multicolumn{3}{|c|}{ Lung cancer deaths (cases) } & \multicolumn{2}{|c|}{ Death reduction [cases (\%)] } \\
\hline & & & Low-dose CT & Chest X-ray & No screening & $\begin{array}{l}\text { Low-dose CT } \\
\text { over chest X-ray }\end{array}$ & $\begin{array}{l}\text { Low-dose CT } \\
\text { over no screening }\end{array}$ \\
\hline $45-70$ & 589.2 & 70.2 & 346 & 417 & 454 & $71(17.0)$ & $108(23.8)$ \\
\hline $45-75$ & 675.4 & 84.7 & 395 & 477 & 521 & $82(17.2)$ & $126(24.2)$ \\
\hline $45-80$ & 766.6 & 100.0 & 448 & 541 & 591 & $93(17.2)$ & $143(24.2)$ \\
\hline $50-70$ & 777.0 & 61.6 & 454 & 549 & 599 & $95(17.3)$ & $145(24.2)$ \\
\hline $50-75$ & 890.0 & 76.0 & 519 & 628 & 686 & $109(17.4)$ & $167(24.3)$ \\
\hline $50-80$ & 1009.4 & 91.3 & 588 & 712 & 778 & $124(17.4)$ & $190(24.4)$ \\
\hline $55-70$ & 967.8 & 49.5 & 564 & 683 & 746 & $119(17.4)$ & $182(24.4)$ \\
\hline $55-75$ & 1115.6 & 63.9 & 649 & 787 & 860 & $138(17.5)$ & $211(24.5)$ \\
\hline $55-80$ & 1270.4 & 79.3 & 738 & 896 & 980 & $158(17.6)$ & $242(24.7)$ \\
\hline $60-70$ & 1263.0 & 32.9 & 734 & 891 & 974 & 157 (17.6) & $240(24.6)$ \\
\hline $60-75$ & 1469.2 & 47.3 & 852 & 1036 & 1133 & $184(17.8)$ & $281(24.8)$ \\
\hline $60-80$ & 1680.2 & 62.7 & 974 & 1185 & 1296 & $211(17.8)$ & $322(24.8)$ \\
\hline
\end{tabular}

a Proportion of lung cancer patients within the listed age interval among all lung cancer patients aged $45-80$ years in urban China

The age interval of 50-75 years currently recommended by the Chinese expert consensus for lung cancer screening [20] covered $76.0 \%$ of all lung cancer patients aged 45-80 years, but the reduction in lung cancer deaths with low-dose CT screening was relatively low, 109 (17.4\%) and 164 (24.3\%), respectively, as compared with chest $\mathrm{X}$-ray screening and no screening.

\section{Influence of smoking and sex criteria}

Figure 3 shows that when not restricted to smokers, the reduction in lung cancer deaths with low-dose CT screening over chest X-ray screening and no screening increased in parallel with the proportion of smokers in the screened cohort, both among men and women.
For example, compared with no screening, the relative reduction in lung cancer deaths among men undergoing low-dose CT screening increased from $23.2 \%$ for non-smokers to $24.2 \%$ for smokers, and the absolute screening benefit doubled from 69 to 143 fewer deaths. Similarly, the absolute benefit gained by low-dose CT screening also doubled compared with chest X-ray screening (from 45 to 93 fewer deaths) for men. Notably, among women the relative reduction in lung cancer deaths with low-dose CT screening was as great as that for men when screening $100 \%$ smokers $(24.2 \%$ over no screening and $17.2 \%$ over chest X-ray screening), and the absolute reduction in lung cancer deaths with low-dose CT screening almost tripled both compared with no

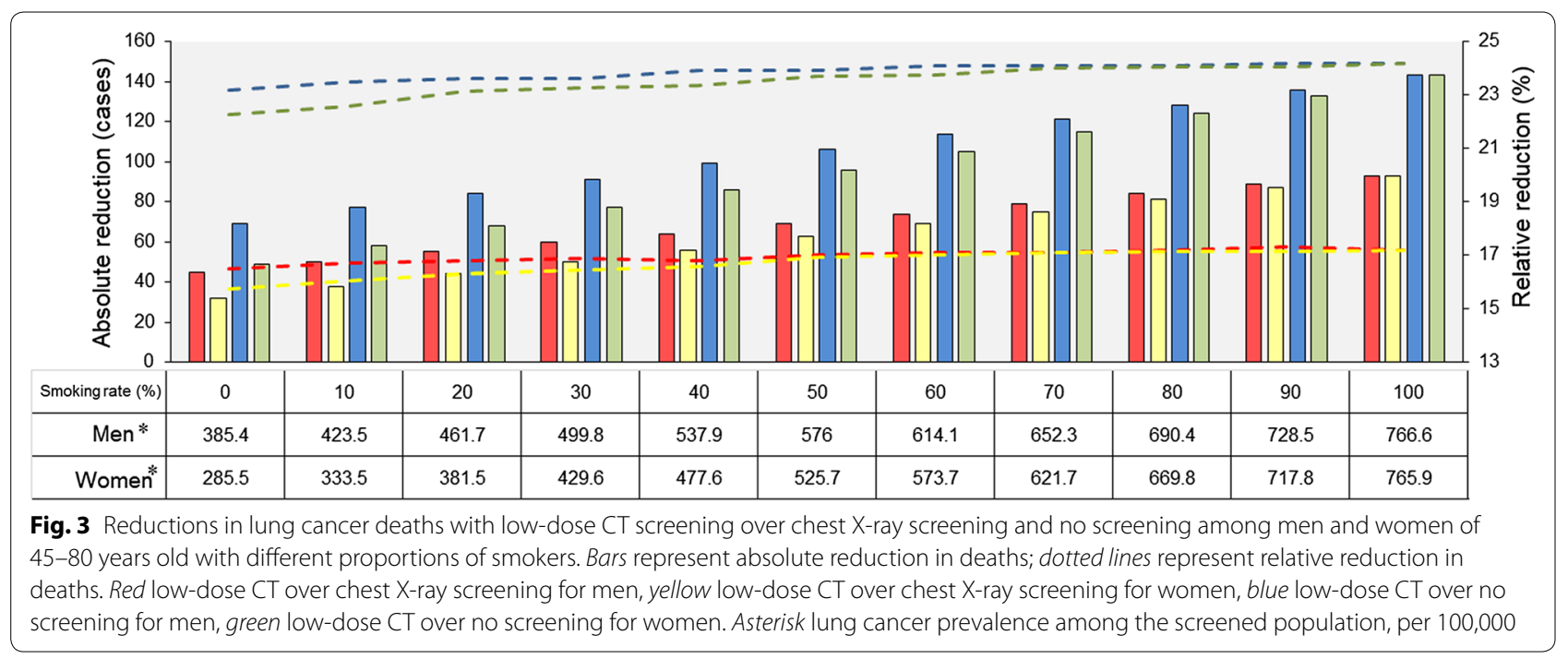


screening (from 49 in non-smokers to 143 in smokers) and chest X-ray screening (from 32 to 93).

\section{Discussion}

This study evaluated the outcomes of lung cancer screening in China, including the influences of several factors on screening effects. According to the base-case analysis of 100,000 urban smokers aged 45-80 years, low-dose CT screening decreased lung cancer deaths by $24.2 \%$ over no screening and by $17.2 \%$ over chest $\mathrm{X}$-ray screening. There were fewer deaths even in the worst case analysis (lung cancer deaths of 245 vs 269 for low-dose CT screening and no screening, respectively; $8.9 \%$ relative reduction), and the reduction was as high as $43.6 \%$ (lung cancer deaths of 364 vs 645 in low-dose CT screening and no screening, respectively) in an optimal situation. Thus, in terms of mortality outcome, our findings indicate that screening old smokers in urban China with low-dose CT would reduce lung cancer deaths. However, the effect of low-dose CT screening on lung cancer death reduction was inferior to that of chest X-ray screening in the worst situation (lung cancer deaths of 281 vs 270 for lowdose CT and chest X-ray screenings, respectively; $-4.1 \%$ relative reduction). On average, low-dose CT screening resulted in more than three-fold false diagnoses and even deaths due to false diagnosis and over-treatment. Additionally, the gain in QALYs with low-dose CT screening (250 years over no screening and 147 years over chest $\mathrm{X}$-ray screening) was not as pronounced as that for mortality. Thus, better screening strategies are required to optimize the outcomes of low-dose CT screening.

Being a country with a large lung cancer burden (with more than 3,500,000 new cases and more than 2,000,000 fatal cases each year [37]), China has a considerable interest in the detection of early-stage lung cancer and prevention of lung cancer deaths via screening $[16,17]$. Several studies have published preliminary results for the comparative ability of low-dose CT screening over chest X-ray screening to detect lung cancer and for other screening variables such as screening-detected cancer stage, pathological, and individual characteristics [16, 38]. In 2010, a demonstration program was initiated at three centers to test the feasibility of conducting population-based screening [39]. Two years later, the government incorporated urban lung cancer screening into a key national public health program [16]. Since 2013, approximately 8000 Beijing citizens have been screened in another program for 3 years using low-dose CT to optimize the screening protocol [16]. Most studies have reported rates of detection, early diagnosis, and early treatment as the main outcomes; however, none have yet reported the endpoint of lung cancer mortality, both because it takes so long to obtain this important but time-consuming endpoint of screening and because a great many participants are needed to identify mortality differences at a low cancer prevalence. Thus, this analysis of currently available domestic data can provide information to the current screening practice before mortality outcome studies are available in China (which will not be very soon). The failure of small trials in Europe to detect any reduction in mortality has usually been attributed to insufficient in subject number (fewer than 2000 in low-dose CT arms) [7-9]. Only the statistically powered NLST study, with a sample size of 53,454, has detected a $20 \%$ mortality reduction with low-dose CT screening over chest X-ray screening [5], which was why we simulated 100,000 participants to obtain robust results. The relatively smaller reduction in lung cancer deaths of $17.2 \%$ with low-dose CT screening over chest X-ray screening in the present study compared with the $20 \%$ in the NLST may be attributable to differences in enrollment criteria [40] (such as smokers in the present study and heavy smokers in the NLST), other population characteristics, and quality of healthcare services.

In the present study, sensitivity analysis showed that the prevalence of lung cancer in the screened cohort was the factor with the strongest influence on reduction in lung cancer deaths, indicating that the selection criteria for eligibility for lung cancer screening programs should be carefully and rigorously defined [40]. Although higher upper age limits for screening eligibility were related with greater reduction in mortality, individuals aged 75 years and older are more vulnerable than younger persons to clinical interventions such as invasive diagnostic and treatment procedures and are at high risk of death from other diseases (such as cardiac arrest and stroke). Thus, screening among this old population potentially affects the actual benefit from screening and may lead to ethical issues. Conversely, enrolling young individuals in screening programs results in only small gains from the perspective of screening service providers. Thus, a balance between risk and gain should be sought when selecting the age range to be screened. We recommend a mid-range spread, say $55-75$ years: this age range has a relatively high screening benefit $(24.5 \%$ reduction in lung cancer deaths with low-dose CT screening over no screening) and provides a relatively high coverage of those likely to have lung cancer $(63.9 \%$ of those aged $45-80$ years). As to the smoking criteria, we found that reductions in lung cancer deaths increase in parallel with the proportion of smokers in both men and women in the smoking cohort. We therefore strongly recommend consideration of low-dose CT screening for lung cancer in regions with high tobacco smoking rates, whereas regions with limited investment in screening should primarily target smokers. Additionally, the reduction 
in lung cancer deaths was not quite pronounced in this study with the relaxed inclusion criteria. It is noteworthy that when the emphasis is on heavy smokers and other criteria for screening are imposed (such as those in the Chinese Consensus on Early Diagnosis of Primary Lung Cancer [20]), a greater screening benefit can be expected compared with nonselective criteria [40]. Considering the important contribution of lung cancer prevalence to screening benefit, a combination of other methods such as biomarkers to identify high-risk individuals would also likely to increase screening benefits [41].

Regarding other factors that influenced screening effects, the sensitivity of low-dose CT had a relatively important positive influence on the reduction in lung cancer deaths; so was the proportion of early-stage cancer among lung cancers detected with low-dose CT screening, reinforcing the need to develop highly sensitive screening techniques [42]. The positive relationship between survival possibility after early treatment of cancer and reduction in deaths emphasizes the need to improve the effectiveness of early treatment to achieve better prognoses and screening benefits. Given the effect of acceptance of treatment on outcomes, screening programs should also consider incorporating approaches to enhancing willingness and financial ability of patients with lung cancer to undergo recommended treatment, particularly in developing countries. Additionally, our findings indicate that survival rates of non-early-stage cancer patients have a very limited impact on mortality outcomes.

For individuals who do not have lung cancers, false positive results remain the most critical issue of low-dose CT screening [43-45]. This is reinforced by the higher numbers of false diagnoses and deaths due to false diagnosis with low-dose CT screening compared with chest X-ray screening in the present study. Because the specificity of low-dose CT directly influences such outcomes, further efforts should be put into increasing the discriminative ability of imaging techniques and their computer-aided diagnostic systems [46], developing optimal diagnostic thresholds $[44,45]$, and employing other imaging techniques (such as positron emission tomography) [47] or other non-imaging approaches (such as highly specific biomarkers) [41, 48, 49]. Additionally, standardization of workflow for diagnosis and treatment, in addition to screening, is indispensable to eliminating unnecessary cost and morbidities associated with lung cancer screening programs [50].

In our study, gains in QALYs of low-dose CT screening over chest X-ray screening and no screening were less impressive than reduction in lung cancer deaths. This was mainly because unscreened individuals with lung cancer can enjoy a higher quality of life during the symptom-free interval before diagnosis of their cancers, whereas individuals with false-positive diagnoses experience a decreased quality of life as a result of anxiety and unnecessary diagnosis or treatment. For example, in the base-case analysis, these two sources resulted in loss of 562 QALYs in the low-dose CT screening scenario than in the no screening scenario (counterbalanced primarily by the stage-shift benefit of 812 QALYs, which led to the final 250-year gain). Thus, close attention should also be paid to physiological reactions if we wish to provide participants in the low-dose CT screening scenario with better quality of life [51].

Limitations remain in this study. First, the decision tree we used is a simplified representation of complex clinical paths and individuals' behaviors. For example, we dichotomized the distribution of cancer stages into early and non-early; full I-IV staging (especially with associated differences in survival) would have made the model more accurate. This was mainly because of lack of large domestic studies from which we could draw robust estimates of screening and clinical parameters. Additionally, the absence of transition possibilities in lung cancer stage among the extremely heterogeneous histological types of lung cancer prevented us from employing stage transition Markov models. Second, for the same reasons, we only considered baseline screening in this study, whereas some programs in China already adopted a baseline and annual repeat screening fashion [52], in which higher proportion of early-stage lung cancers in repeat rounds could be expected. Thus, longitudinal screening parameters from such programs and their impact on mortality reduction are highly needed for further decision analyses. Third, although false diagnoses, missed diagnoses, and over-diagnoses of indolent cancers were considered, we did not consider complex issues such as passive smoking and competing risk from other diseases in old individuals, but left these for future studies. Finally, the lack of expenditure data at the national level and differences in costs of lung cancer treatment between different regions thus far prevents evaluation of the cost-effectiveness of lung cancer screening. Thus, the balance between input and yield requires further in-depth evaluation.

\section{Conclusions}

Mortality outcome derived from this decision analysis were in favor of conducting low-dose CT screening in urban China for early detection and treatment of lung cancer. However, for nationwide promotion in the future, further work should be done to optimize the effects of screening, minimize false positive diagnoses, and improve participants' actual quality of life, such as by developing selection criteria for screening that are more appropriate to Chinese participants, standardizing diagnostic and treatment 
methods, and adapting screening protocols according to availability of funding and other local conditions.

\section{Authors' contributions}

$J J$ and CZ conceptualized this study. FX and WS formulated the overall study design. YW, YH, and LW did the literature review and participated in the metaanalysis. YH, SZ, and XS participated in constructing the decision tree and provided considerable input to the discussion of practical implication. ZW and WH performed the formal analysis and wrote the manuscript. WZ contributed greatly to writing the final draft. RS validated the analysis results and refined the manuscript. All authors read and approved the final manuscript.

\section{Author details}

${ }^{1}$ Institute of Basic Medical Sciences, Chinese Academy of Medical Sciences, Beijing 100005, P. R. China. ${ }^{2}$ Cancer Hospital, Chinese Academy of Medical Sciences, Beijing 100021, P. R. China. ${ }^{3}$ Peking Union Medical College Hospital, Chinese Academy of Medical Sciences, Beijing 100730, P. R. China. ${ }^{4}$ National Institutes for Food and Drug Control, State Food and Drug Administration, Beijing 100050, P. R. China.

\section{Acknowledgements \\ Not applicable.}

\section{Competing interests}

The authors declare that they have no competing interests.

\section{Funding}

This study was supported by Peking Union Medical College Youth Fund and the Fundamental Research Funds for the Central Universities (No. 2017310049).

Received: 29 August 2016 Accepted: 16 January 2017

Published online: 14 July 2017

\section{References}

1. Chen W, Zheng R, Baade PD, Zhang S, Zeng H, Bray F, et al. Cancer statistics in China, 2015. CA Cancer J Clin. 2016;66(2):115-32. doi:10.3322/ caac. 21338

2. American Cancer Society. Cancer facts \& figures 2014. http://www.cancer. org/research/cancerfactsstatistics/cancerfactsfigures2014/. Accessed 28 Aug 2016.

3. Liang W, Shao W, Jiang G, Wang Q, Liu L, Liu D, et al. Chinese multi-institutional registry (CMIR) for resected non-small cell lung cancer: survival analysis of 5,853 cases. J Thorac Dis. 2013;5(6):726-9. doi:10.3978/j. issn.2072-1439.2013.12.32.

4. Wood DE, Eapen GA, Ettinger DS, Hou L, Jackman D, Kazerooni E, et al. Lung cancer screening. J Natl Compr Canc Netw. 2012;10(2):240-65.

5. National Lung Screening Trial Research Team, Aberle DR, Adams AM, Berg CD, Black WC, Clapp JD, et al. Reduced lung-cancer mortality with lowdose computed tomographic screening. N Engl J Med. 2011;365(5):395409. doi:10.1056/NEJMoa1102873.

6. Nawa T, Nakagawa T, Mizoue T, Kusano S, Chonan T, Hayashihara K, et al. A decrease in lung cancer mortality following the introduction of low-dose chest CT screening in Hitachi, Japan. Lung Cancer. 2012;78(3):225-8. doi:10.1016/j.lungcan.2012.09.012.

7. Infante M, Cavuto S, Lutman FR, Brambilla G, Chiesa G, Ceresoli G, et al. A randomized study of lung cancer screening with spiral computed tomography. Am J Respir Care Med. 2009:180(5):445-53. doi:10.1164/ rccm.200901-00760C.

8. Pastorino U, Rossi M, Rosato V, Marchianò A, Sverzellati N, Morosi C, et al. Annual or biennial CT screening versus observation in heavy smokers: 5-year results of the MILD trial. Eur J Cancer Prev. 2012;21(3):308-15. doi:10.1097/CEJ.0b013e328351e1b6.

9. Saghir Z, Dirksen A, Ashraf H, Bach KS, Brodersen J, Clementsen PF, et al. CT screening for lung cancer brings forward early disease. The randomised Danish Lung Cancer Screening Trial: status after five annual screening rounds with low-dose CT. Thorax. 2012;67(4):296-301. doi:10.1136/thoraxjnl-2011-200736.

10. Becker N, Motsch E, Gross ML, Eigentopf A, Heussel CP, Dienemann H, et al. Randomized study on early detection of lung cancer with MSCT in Germany: results of the first 3 years of follow-up after randomization. J Thorac Oncol. 2015;10(6):890-6. doi:10.1097/JTO.0000000000000530.

11. Lopes Pegna A, Picozzi G, Falaschi F, Carrozzi L, Falchini M, Carozzi FM, et al. Four-year results of low-dose CT screening and nodule management in the ITALUNG trial. J Thorac Oncol. 2013;8(7):866-75. doi:10.1097/ JTO.0b013e31828f68d6.

12. Blanchon T, Bréchot JM, Grenier PA, Ferretti GR, Lemarié E, Milleron B, et al. Baseline results of the Depiscan study: a French randomized pilot trial of lung cancer screening comparing low-dose CT scan (LDCT) and chest X-ray (CXR). Lung Cancer. 2007;58(1):50-8.

13. Horeweg N, Scholten ET, de Jong PA, van der Aalst CM, Weenink C, Lammers JW, et al. Detection of lung cancer through low-dose CT screening (NELSON): a prespecified analysis of screening test performance and interval cancers. Lancet Oncol. 2014;15(12):1342-50. doi:10.1016/ S1470-2045(14)70387-0.

14. McRonald FE, Yadegarfar G, Baldwin DR, Devaraj A, Brain KE, Eisen T, et al. The UK lung screen (UKLS): demographic profile of first 88,897 approaches provides recommendations for population screening. Cancer Prev Res (Phila). 2014;7(3):362-71. doi:10.1158/1940-6207.CAPR-13-0206.

15. Globocan 2012: Estimated cancer incidence, mortality and prevalence worldwide in 2012. http://globocan.iarc.fr/Default.aspx. Accessed 28 Aug 2016.

16. Zhao SJ, Wu N. Early detection of lung cancer: low-dose computed tomography screening in China. Thorac Cancer. 2015;6(4):385-9. doi:10.1111/1759-7714.12253

17. World Health Organization. Global heath observatory (GHO) data. http:// www.who.int/gho/health_workforce/en/. Accessed 28 Aug 2016.

18. Sampling survey data of the national population change in 2013. In: China Population \& Employment Statistics Yearbook 2014. China Economic and social development statistics database. http://tongji.cnki.net/ kns55/Navi/result.aspx?id =N2016010131\&file $=$ N2016010131000039\&fl oor $=1$. Accessed 11 Dec 2016.

19. Chen W, He J. Annual report of cancer registration in China 2012. Beijing: Military Medical Science Press; 2012.

20. Zhou QH, Fan YG, Bu H, Wang Y, Wu N, et al. China national lung cancer screening guideline with low-dose computed tomography (2015 version). Thorac Cancer. 2015;6(6):812-8.

21. Zhang M, Wang LM, Li YC, Li XY, Jiang Y, Hu N, et al. Cross-sectional survey on smoking and smoking cessation behaviors among Chinese adults in 2010. Chin J Prev Med. 2012;46(5):404-8. doi:10.3760/cma.j.i ssn.0253-9624.2012.05.006 (in Chinese).

22. Moussa M, Ruwanpura JY, Jergeas G. Decision tree module within decision support simulation system. In: Proceedings of the IEEE simulation conference. 2004. p. 1268-76

23. Burton A, Altman DG, Royston P, Holder RL. The design of simulation studies in medical statistics. Stat Med. 2006;25(24):4279-92.

24. Reich JM. A critical appraisal of overdiagnosis: estimates of its magnitude and implications for lung cancer screening. Thorax. 2008;63(4):377-83. doi:10.1136/thx.2007.079673.

25. Hurria A, Kris MG. Management of lung cancer in older adults. CA Cancer J Clin. 2003;53(6):325-41.

26. CDC China. Global adult tobacco survey (GATS) China 2010 country report. Shanghai: China Three Gorges Press; 2011 (in Chinese)

27. Zhong L, Goldberg MS, Gao YT, Hanley JA, Parent ME, Jin F. A populationbased case-control study of lung cancer and green tea consumption among women living in Shanghai, China. Epidemiology. 2001;12(6):695-700.

28. Hu J, Galeone C, Lui R, Pelucchi C, La Vecchia C, Negri E. Smoking and lung cancer in Harbin, Northeast China. Ann Oncol. 2005;16(10):1605-8.

29. Wang $\mathrm{H}$. Association of human aryl hydrocarbon receptor gene polymorphisms with risk of lung cancer among cigarette smokers in a Chinese population. Pharmacogenet Genom. 2008;19(1):25-34.

30. Li Y, Chang SC, Niu R, Liu L, Crabtree-Ide CR, Zhao B, et al. TP53 genetic polymorphisms, interactions with lifestyle factors and lung cancer risk: a case control study in a Chinese population. BMC Cancer. 2013;251(1):22-32

31. Xun X, Wang H, Yang H, Wang H, Wang B, Kang L, et al. CLPTM1L genetic polymorphisms and interaction with smoking and alcohol drinking in 
lung cancer risk: a case-control study in the han population from Northwest China. Medicine. 2014;93(28):e289.

32. Goldstraw P, Chansky K, Crowley J, Rami-Porta R, Asamura H, Eberhardt WE, et al. The IASLC lung cancer staging project: proposals for revision of the TNM stage groupings in the forthcoming (Eighth) edition of the TNM classification for lung cancer. JThorac Oncol. 2016;1 1(1):39-51. doi:10.1016/j.jtho.2015.09.009.

33. Drummond MF, Sculpher MJ, Claxton K, et al. Methods for the economic evaluation of health care programmes. 4th ed. Oxford: OUP; 2015.

34. Zhao Y, Lu RZ. Study on quality adjusted life years of old people in Chinese communities. Proc Clin Med. 2006;15(12):948-9. doi:10.3969/j. issn. 1671-8631.2006.12.052 (in Chinese)

35. Manser RL, Wright G, Byrnes G, Hart D, Conron M, Carter R. Validity of the assessment of quality of life (AQoL) utility instrument in patients with operable and inoperable lung cancer. Lung Cancer. 2006;53(2):217-29.

36. Fang MY. Clinical investigation of lung cancer: a retrospective analysis of 3751 in Zhejiang Province Cancer Hospital. Zhejiang: Zhejiang University; 2007 (in Chinese).

37. Chen $W$, Zheng R, Zeng H, Zhang S. The incidence and mortality of major cancers in China, 2012. Chin J Cancer. 2016;35(1):430-4.

38. Tang W, Wu N, Huang Y, Zhao $S$, Xu Z, et al. Results of low-dose computed tomography (LDCT) screening for early lung cancer: prevalence in 4690 asymptomatic participants. Chin J Oncol. 2014;36(7):549-54 (in Chinese).

39. Zhou $Q$, Fan $Y$, Wu N, Huang Y, Wang Y, Li L, et al. Demonstration program of population-based lung cancer screening in China: rationale and study design. Thorac Cancer. 2014;5(3):197-203. doi:10.1111/1759-7714.12078.

40. Tammemägi MC, Katki HA, Hocking WG, Church TR, Caporaso N, Kvale $\mathrm{PA}$, et al. Selection criteria for lung-cancer screening. N Engl I Med. 2013;368(8):728-36. doi:10.1056/NEJMoa1211776.

41. Xiang D, Zhang B, Doll D, Shen K, Kloecker G, Freter C. Lung cancer screening: from imaging to biomarker. Biomark Res. 2013;1 (1):4. doi:10.1186/2050-7771-1-4.

42. Nunzio GD, Tommasi E, Agrusti A, Cataldo R, Mitri ID, Favetta M, et al. An innovative lung segmentation algorithm in CT images with accurate delimitation of the hilus pulmonis. In: IEEE nuclear science symposium conference. 2008. p. 5359-61.

43. Kauczor HU, Bonomo L, Gaga M, Nackaerts K, Peled N, Prokop M, et al. ESR/ERS white paper on lung cancer screening. Eur Radiol. 2015:25(9):2519-31. doi:10.1007/s00330-015-3697-0.

44. Gierada DS, Pinsky P, Nath H, Chiles C, Duan F, Aberle DR. Projected outcomes using different nodule sizes to define a positive CT lung cancer screening examination. J Natl Cancer Inst. 2014. doi:10.1093/ jnci/dju284.

45. Heuvelmans MA, Oudkerk M, de Bock GH, de Koning HJ, Xie X, van Ooijen PM, et al. Optimisation of volume-doubling time cutoff for fast-growing lung nodules in CT lung cancer screening reduces false-positive referrals. Eur Radiol. 2013;23(7):1836-45. doi:10.1007/s00330-013-2799-9.

46. Brown MS, Lo P, Goldin JG, Barnoy E, Kim GH, McNitt-Gray MF, et al. Toward clinically usable CAD for lung cancer screening with computed tomography. Eur Radiol. 2014;24(11):2719-28. doi:10.1007/ s00330-014-3329-0.

47. Ashraf H, Dirksen A, Loft A, Bertelsen AK, Bach KS, Hansen H, et al. Combined use of positron emission tomography and volume doubling time in lung cancer screening with low-dose CT scanning. Thorax. 2011;66(4):315-9. doi:10.1136/thx.2010.136747.

48. Hasan N, Kumar R, Kavuru MS. Lung cancer screening beyond lowdose computed tomography: the role of novel biomarkers. Lung. 2014;192(5):639-48. doi:10.1007/s00408-014-9636-z.

49. Li Y, Li X. Global efforts in conquering lung cancer in China. Chin J Cancer. 2015:34(3):320-2.

50. Mazzone P, Powell CA, Arenberg D, Bach P, Detterbeck F, Gould MK, et al. Components necessary for high-quality lung cancer screening: American College of Chest Physicians and American Thoracic Society policy statement. Chest. 2015;147(2):295-303. doi:10.1378/chest.14-2500.

51. Quaife $S L$, Janes $S M$. Lung cancer screening: improving understanding of the psychological impact. Thorax. 2016;71(11):971-2. doi:10.1136/ thoraxinl-2016-208966.

52. Zhao F, Xu M, Lei H, Zhou Z, Wang L, Li P, et al. Clinicopathological characteristics of patients with non-small-cell lung cancer who harbor EML4-ALK fusion gene: a meta-analysis. PLoS ONE. 2014;10(2):e01 17333.
53. He RX, Zhou YH. Application value of 64 slice spiral CT low-dose lung examination for early lung cancer screening. Health Way. 2015;14(8):15 (in Chinese)

54. Yin RG, Wang DQ, Zhao L, Gan Q, Sun WB, Peng WB, et al. The analysis of feasibility of low-dose thin section multi-slice helical CT in screening for lung cancer. J Pract Radiol. 2005;20(4):370-3 (in Chinese).

55. Zhan X. Comparative study of diagnostic value of $X$-ray and $C T$ in lung cancer. J Mod Clin Med. 2005;31(4):238-9 (in Chinese).

56. Yang $M$, Wang J, Meng $L$, Wang Y, Xu L, Liu FY, et al. Analysis of feasibility of lung cancer screening with low-radiation-dose spiral CT scan plus detection of p16 gene methylation in serum. Chin J Cancer Prev Treat. 2008;15(1):8-10. doi:10.16073/j.cnki.cjcpt.2008.01.010 (in Chinese)

57. Huang MG, Wang Q, Qi M, Wu XH. Diagnostic value on lung cancer screening using low-dose spiral CT. J Pract Radiol. 2008;24(8):1030-3 (in Chinese).

58. Qiu Y, Je JX, Cheng XY, Chen HZ, Ge LH, Wei B, et al. Low-dose spiral CT screening for lung cancer: Guangzhou experience. Acad I Guangzhou Med Coll. 2007;35(1):39-42. doi:10.3969/j.issn.1008-1836.2007.01.011 (in Chinese).

59. Li J. Analysis of 433 cases of lung cancer with digital chest radiography Suzhou Univ J Med Sci. 2010;30(4):846-7 (in Chinese).

60. Wang GW. Application value of chest low-dose spiral CT for screening pulmonary nodules in healthy population. Clin Educ Gen Pract. 2014;12(6):633-5. doi:10.13558/j.cnki.issn1672-3686.2014.06.010 (in Chinese).

61. Yan Z, Wang YJ, Xu HY, Ma LH. Application value of low dose spiral CT scanning in the diagnosis of early lung cancer. Chin J Clin Ration Drug Use. 2014;7(13):122-3 (in Chinese)

62. Dong L, Zhang XH, Han LL, Liu Z. Study of diagnosis of chest X ray, CT and bronchoscopy in lung cancer. China Foreign Med Treat. 2015;34(27):17980. doi:10.3969/j.issn.1674-0742.2015.27.083 (in Chinese).

63. Gong GZ. Comparative analysis of the effect of X-ray and CT scanning in diagnosis of central lung cancer. Guide China Med. 2015;13(31):136 (in Chinese).

64. Li FZ, Zou NA, Hu HM, Wu QH, Ou YL. Low-dose spiral CT combined tumor markers for lung cancer screening high-risk groups. Jiangxi Med J. 2015;50(5):384-7. doi:10.3969/j.issn. 1006-2238.2015.05.004 (in Chinese).

65. Liu J. Value of different imaging methods in diagnosis of primary lung cancer. China Prac Med. 2016;1 1(7):55-6. doi:10.14163/j.cnki.115547/r.2016.07.038 (in Chinese).

66. Lei Y, Chen BJ, Zeng L, Li WM. Application value of chest digital radiography in screening lung-cancer among high-risk group. Chinese general practice.

67. Shi LX. Comparison of the diagnostic value of spiral CT and chest X-ray in lung cancer. J Bethune Mil Med Coll. 2014;12(3):292-4 (in Chinese).

68. Wang $X$, Hong N, Sun C. Chest X-ray digital radiography in screening for heart and lung disease for middle-aged and elderly population in Beijing area. Chin J Med Imag Technol. 2013;29(2):213-6 (in Chinese).

69. Li YZ. Application value of chest digital radiography and low-dose spiral CT in screening of lung cancer. Chin J Prev Contr Chron Dis. 2015;23(6):463-4. doi:10.16386/j.cjpccd.issn. 1004-6194.2015.06.019 (in Chinese).

70. Lei Y, Chen BJ, Zeng L, LiWM. Application value of low-dose computed tomography for the screening of lung-cancer in high-risk group. Sichuan Da Xue Xue Bao Yi Xue Ban. 2012;43(4):584-7 (in Chinese).

71. Yan Z, Wang YJ, Xu HY, Ma LH. The value of low-dose spiral CT in the diagnosis of lung cancer in high risk population. Chin J Clin Ration Drug Use. 2014;7(10):151 (in Chinese).

72. Wu JM. Clinical value of low-dose and conventional-dose 6-slice spiral $\mathrm{CT}$ in the diagnosis of patients with lung cancer. J Clin Pulm Med. 2013;18(5):796-7. doi:10.3969/j.issn.1009-6663.2013.05.010.

73. Wang Z, Hu Y, Wang Y, Han W, Wang L, Xue F, et al. Can CT screening give rise to a beneficial stage shift in lung cancer patients? Systematic review and meta-analysis. PLOS ONE. 2016;11(10):e0164416.

74. National Lung Screening Trial Research Team. Results of initial lowdose computed tomographic screening for lung cancer. N Engl J Med. 2013;368(21):1980-91.

75. Wang ZWS. EGFR mutations in patients with non-small cell lung cancer from mainland China and their relationships with clinicopathological features: a meta-analysis. Int J Clin Exp Med. 2014;7(8):1967-78 (in Chinese) 
76. Shao Q, Jianbin L, Fengxiang L, Wang S, Wang W, Liu S, et al. Clinical investigation into the initial diagnosis and treatment of 1,168 lung cancer patients. Oncol Lett. 2015;9(2):563-8.

77. Fan H, Shao ZY, Xiao YY, Xie ZH, Chen W, Xie H, et al. Incidence and survival of non-small cell lung cancer in Shanghai: a population-based cohort study. BMJ Open. 2015;5(12):e009419.

78. Wang N, Yang L, Yuan XM, Sun TT, Yuan YN. Investigation on the diagnosis of lung cancer inpatients in Beijing city in 2008. Chin J Prev Med. 2013:47(3):278-9 (in Chinese).

79. Zhao S, Li L, Qiu ZX, Chen Y, Jing Y, Zhou Y, et al. Clinical epidemiology and histological characteristics of 3,663 lung cancer patients in sichuan province from 2008 to 2013. Chin J Lung Cancer. 2016;19(2):70-6.

80. Zhang HB, Zhao JH, Bai L, Su HX, Zhao YX. An analysis on clinicopathological data of surgery and non-surgery treatment for patients with primary lung carcinoma. J Mod Oncol. 2012;20(7):1378-80. doi:10.3969/j. issn.1672-4992.2012.07.21 (in Chinese).

81. Yuan LZ, Zhang J, Tan H, Zhou W, Li XZ, Yang X. An analysis of 1657 inpatients with lung cancer from 2001 to 2008. J Ningxia Med Univ. 2010;32(3):374-7. doi:10.3969/j.issn.1674-6309.2010.03.018 (in Chinese).

82. Wu Y. Clinical features and prognostic analysis of the primary lung cancer patients experience at Fujian from 2009-2012. Fujian Med Univ. 2013. (in Chinese).

83. Wei WD, Wen ZS, Su XD, Lin P, Rong TH, Chen LK. Multivariate survival analysis of 899 patients with non-small cell lung cancer after complete resection. Chin J Cancer. 2007;26(11):1231-6. doi:10.3321/j. issn:1000-467x.2007.11.015.

84. Xiao YH, Zhang WJ, Han XW. Prognostic analysis of 1091 patients with lung cancer. J Pract Cancer. 2000;15(6):626-8 (in Chinese).

85. Zhang X, Zhang S, Yang X, Yang J, Zhou Q, Yin L, et al. Fusion of EML4, and ALK, is associated with development of lung adenocarcinomas lacking EGFR, and KRAS, mutations and is correlated with ALK expression. Mol Cancer. 2010;9(1):1-12.

86. Lin XM, Mo JM, Zou M, Zeng AP, Yu QT, Zhou SZ, et al. Detection of EML4ALK fusion gene and analysis of its clinical features in NSCLC patients with EGFR mutation. Chin J Pathophysiol. 2012;28:1135-9 (in Chinese).

87. Zhang YG, Jin ML, Li L, Zhao HY, Zeng X, Jiang L, et al. Evaluation of ALK rearrangement in Chinese non-small cell lung cancer using FISH, immunohistochemistry, and real-time quantitative RT-PCR on paraffinembedded tissues. PLOS ONE. 2013;8(5):e64821.

88. Zhong S, Zhang HP, Zheng J. Detection of EMIA-ALK fusion gene in nonsmall cell lung cancer and its clinicopathologic correlation. Chin J Pathol. 2013;42:252-6 (in Chinese)

89. Wang M, Yang JY, Li JC, Chen YX. Expression of EML4-ALK in non-small cell lung cancer and its clinical significance. Chin Clin Oncol. 2013;18:688-90 (in Chinese)
90. Li Y, Li YG, Yang T, Wei S, Wang J, Wang M, et al. Clinical significance of EML4-ALK fusion gene and association with EGFR and KRAS gene mutations in 208 Chinese patients with non-small cell lung cancer. PLoS ONE. 2013;8(1):e52093.

91. Yang JJ, Zhang XC, Su J, Xu CR, Zhou Q, Tian HX, et al. Lung cancers with concomitant EGFR mutations and ALK rearrangements: diverse responses to EGFR-TKI and crizotinib in relation to diverse receptors phosphorylation. Clin Cancer Res. 2014;20:1383-92.

92. Wu Y, Lin J, Wang K. EGFR mutations in lung cancers and sensitivity to gefitinib in Chinese (Abstract). J Clin Oncol. 2005;23:7089.

93. Zhou C, Su B, Zhao Y. Epidermal growth factor receptor mutations in Chinese patients with non-small cell lung cancer. Lung Cancer. 2005;49(Suppl2):S152-3.

94. Zhang J, Liang ZY, Zeng X, Wu SF, Gao J, Liu TH. Detection of epidermal growth factor receptor gene mutations in non-small cell lung cancers by real-time polymerase chain reaction using scorpion amplification refractory mutation system. Zhonghua Bing Li Xue Za Zhi. 2008;37:294-9 (in Chinese).

95. Yin XW, Jiang XT, Yuan YT, Du YP. Influence of mutations in epidermal growth factor receptor gene on growth, metastasis and survival rate of non-small cell lung carcinoma. Zhonghua Yi Xue Za Zhi. 2010;90:1808-12 (in Chinese)

96. An SJ, Chen ZH, Su J, Zhang XC, Zhong WZ, Yang JJ, et al. Identification of enriched driver gene alterations in subgroups of non-small cell lung cancer patients based on histology and smoking status. PLOS ONE. 2012; 7:e40109.

97. Li Y, Li Y, Wang T, Wei S, Wang J, Wong M, et al. Clinical significance of EML4-ALK fusion gene and association with EGFR and KRAS gene mutations in 208 Chinese patients with non-small cell lung cancer. PLOS ONE. 2013;8:e52093.

98. Zhang Y, Wang Q, Han ZG, Shan L. Differences in epidermal growth factor receptor gene mutations and relationship with clinicopathological features in NSCLC between Uygur and Han ethnic groups. Asian Pac J Cancer Prev. 2013;14:2879-83.

99. Lai Y, Zhang Z, Li J, Sun D, Zhou Y, Jiang T, et al. EGFR mutations in surgically resected fresh specimens from 697 consecutive chinese patients with non-small cell lung cancer and their relationships with clinical features. Int J Mol Sci. 2013;14:24549-59.

\section{Submit your next manuscript to BioMed Central and we will help you at every step:}

- We accept pre-submission inquiries

- Our selector tool helps you to find the most relevant journal

- We provide round the clock customer support

- Convenient online submission

- Thorough peer review

- Inclusion in PubMed and all major indexing services

- Maximum visibility for your research

Submit your manuscript at www.biomedcentral.com/submit
BioMed Central 